\title{
With a personal appearance from the online teacher
}

\author{
Christine Sinclair(D)
}

\author{
Correspondence: \\ Christine.Sinclair@ed.ac.uk \\ Institute for Education, Community \\ and Society, Moray House School of \\ Education, University of Edinburgh, \\ Room 4.17, St John's Land, \\ Edinburgh EH8 8AQ, Scotland, UK
}

\begin{abstract}
While online students may wish to see their teacher on video, there may be practical, pedagogical, affective or political reasons for hesitating. Drawing on my own experiences of online teaching both on a Masters programme and a MOOC (EDCMOOC), the paper raises questions about approaches to teaching, misrepresentation, surveillance and teacher agency. I conclude that though there are problems in these areas, they exist apart from the use of video technology and should not be conflated with it. Moreover, video use does not need to entail a monologic pedagogic stance but can be used to renew and create dialogic opportunities for teachers and students. The paper situates its questions within Bakhtinian ideas about the monologic and the dialogic, parody and addressivity.
\end{abstract}

Keywords: Dialogic, Bakhtin, MOOC, Presence, Community of inquiry, Parody, Addressivity

\section{Introduction: why do students want to see us?}

It seems that many online Higher Education students now expect and want to see their teachers on video. This paper offers a deeply personal response to students' requests for video appearance, and ties it to pedagogical literature on online teaching. I am particularly interested in whether using video poses a threat to my aspirations for a dialogic approach to pedagogy and indeed to other aspects of academic life. I am influenced by Bakhtin's notions of the authoritative (monologic) discourse and the "internally persuasive" (dialogic) discourse (Bakhtin 1981, pp. 345-346) and take the opportunity to explore how these constructs might be applied to video-based communication. At first sight, a teacher-led video may seem monologic, though of course it does not need to be.

I teach on the University of Edinburgh's MSc in Digital Education, and I am also a graduate of the programme. As a student, 10 years ago, I did not particularly expect to see my teachers through video presentations; however, I have become sensitive in recent years to this wish in current students. This seemed to follow on a couple of years after the proliferation of Massive Open Online Courses (MOOCs) in 2012. Many of our newer students had already participated in MOOCs, including one that my colleagues and I had run, and we wondered whether this had set up expectations that we, the online teachers, would be visible through video, not just through photographs and avatars. Our programme is already highly interactive; our students frequently

(c) The Author(s). 2016 Open Access This article is distributed under the terms of the Creative Commons Attribution 4.0 International License (http://creativecommons.org/licenses/by/4.0/), which permits unrestricted use, distribution, and reproduction in any medium, provided you give appropriate credit to the original author(s) and the source, provide a link to the Creative Commons license, and indicate if changes were made. 
mention the quality of attention from tutors. But it seemed text-based communication might be insufficient for some.

I have recently started to introduce audio and video messages at the beginning of each week in one of my courses. I was immediately informed by some students that this made me seem more "real" and "human". I thought this might simply be a novelty effect, but it has seemed deeper than that and is something I have discussed with my students. Ultimately, I have decided to make the occasional video appearance: I now share the reasons for this and the concerns that may affect how I will do it. It will be interesting to research the effects of increased exposure to online teachers through video, but that is a future study. I supplement the record of my journey towards video appearance in teaching with video extracts from stages on the way. More theoretically, I analyse key points on that journey in terms of Bakhtin's ideas about dialogical relationships.

\section{Transmission or dialogue?}

The MOOC phenomenon certainly brought video lecturing into critical focus for our teaching team. Five members were involved in one of the first six MOOCs in the UK - E-learning and Digital Cultures, hosted on the Coursera platform. E-learning and Digital Cultures - EDCMOOC - ran three times, each for a period of five weeks, in January 2013, November 2013 and November 2014. It was structured around dystopian and utopian past and current visions of digital culture and education, and the shift from humanist to posthumanist perspectives on these themes. Participants were encouraged to watch carefully-selected publicly available short films, to read and, above all, to blog, tweet, create and share. Around 42,000 people signed up for the first run, though this figure kept changing and a large proportion did not actually engage with the site. (For more statistics on this and other early Edinburgh MOOCs see MOOCs@Edinburgh 2013).

In thinking about our teaching approach, we identified that we were "keen to avoid both the over-celebratory fetishizing of the teacher associated with some MOOCs, and the tendency to see the technology as allowing us to write the teacher out of the equation altogether" (Knox et al. 2012). While avoiding these two extremes, we were interested in exploring the impact that teaching at scale would have on our own conception of the teaching role.

In many MOOCs, the "guru professor" tends to deliver a traditional lecture, videorecorded with high production values and with a strong performance, transmitting information in an authoritative or "instructivist" fashion which has long been characterised as being in binary opposition to "constructivist" teaching (for example, Kanuka and Anderson 1999). Nowadays, the professor arguably only needs to speak once to be captured forever on video. Instructivist transmission-based teaching seems retrograde to contemporary educationalists who favour more social constructivist approaches to teaching and learning, where the emphasis is on co-construction of knowledge through interaction with students. Thus there is a general concern that traditionallydesigned MOOCs may promote a form of teaching that is now widely deprecated, even though other models are possible (Macleod et al. 2016). Perhaps the main concern, though, is the inference that the traditional lecture is assumed to be the only valid approach. 
An instructivist lecture, frozen in a video, would seem to encapsulate Bakhtin's idea of the monologic, with its authority already located in - and acknowledged in - the past (Bakhtin 1981), perhaps like a printed textbook. The teaching video, therefore, might seem unpromising for people seeking to be innovative in education. Yet even textbooks and other printed works such as novels can recognize multiple perspectives and voices, as Bakhtin himself illustrated particularly in relation to novels written by Dostoevsky (Bakhtin 1984). The same might apply to video that does not have to be subordinated to a monologic intention.

Our own MOOC experiences provided an opportunity for unprecedented creative engagement with large numbers of participants, generating insights for teaching, including the impact of the visual. Rather than the video-lecture, we shared short films and readings with students for analysis and encouraged production of digital artefacts. The first forum post on our site asked, "Where are the videos?", from a student already accustomed to Coursera's more didactic video lectures. This was fairly soon followed by, "Where are the professors?" which proved an interesting topic in our context of digital cultures. When we did a public synchronous Google hangout at the end of our first week, the response from the students was overwhelming and (nearly) entirely positive. The participants really wanted to see and hear us. They told us so - on Twitter, the Hangout site itself, in our MOOC forums and in YouTube.

For my colleagues and me, it was a rather terrifying though exhilarating experience: sitting in our individual offices talking to (potentially) thousands of people all over the world. As each of us spoke, the viewers were responding and we picked up on those responses with assistance from our own online students who were monitoring the communications. This was certainly not a one-way communication; a visual presence does not have to mean transmission. We took the opportunity to pick up on dialogues started by the students in the MOOC's forums.

Additional file 1: Video S1: Appearance 1: Where are the professors?

\section{Dialogical challenges: criticality, parody and misrepresentation}

The use of the Google hangout, then, served to increase opportunities for dialogue with MOOC participants. It might be suggested that this dialogue was arguably less "dialogic" than some of our other activities. While the social media backchannels allowed response that could be fed back into the conversation, the fleeting nature of the dialogical elements might still have privileged the authority of the teachers. Nevertheless, some authors interested in promoting dialogue, such as O'Connor \& Michaels (2007, p. 277), would recognize an ideological stance towards dialogic discourse: we aimed for the interplay of ideas and meaning and this hangout formed a contribution to multiple chains of dialogue around digital cultures and what we were doing. As these writers point out, the distinction between monologic and dialogic goes beyond linguistic structure. Bakhtin (1984) would agree: monological conventions cannot obliterate Dostoevsky's multivoiced and dialogic writing. Similarly, a lecturer apparently "transmitting" to hundreds of people through a visual medium can still be working dialogically.

EDCMOOC was designed to be dialogic, through resources and activities that would provoke discussion through aggregated blogs, forums, Twitter and other social media. Knox (2016, p. 171) identifies this as a critical response to the video lecture already 
prevalent in certain kinds of MOOC. EDCMOOC was itself encouraging a critical attitude to utopian and dystopian visions of digital culture that participants were likely to encounter. The word "critical", of course, has several associations. Many of the dialogues in EDCMOOC were themselves critical, in many senses of the word, involving judgements not only about digital cultures but also about the structure of the course, its delivery and its teachers.

We did receive some negative comments on our MOOC - it would have been surprising and perhaps worrying if we had not - but we did not experience much inappropriate behaviour, though it did cross our minds. When a "course" has over 40,000 unknown participants, it is not surprising that a teacher thinks about incidences of trolling and contempt that exposure of faces and bodies online can generate. There is a potential loss of control over one's own image, which may be stolen and repurposed. These are well-documented risks of all online activities, in academic literature (for example, Herring et al. 2002) and in more public debate, such as Jon Ronson's disturbing book prompted by a Twitter bot that shared his name (Ronson 2015).

Our own MOOC students did parody us quite a lot; they remixed some of our still and moving images; and indeed one even created a fake Twitter account for one of my colleagues. These activities tended to be done with goodwill, creativity and even permission. We loved it, not least because the parodies made serious intellectual contributions to the many dialogues around digital cultures that were happening in our MOOC. We were not shamed nor threatened by these parodies; they served rather as a reminder of dialogic processes that can emerge from a carnivalesque bringing together of an original voice and the travestied version of it (Bakhtin 1981). Parody is an important feature in Bakhtin's dialogic theory, because it can both reveal meanings and provide a context for collaborating on new interpretations and insights. The playful remixing and parodying of our messages and forms of delivery did not attempt to destroy the original; indeed, they contributed to its continuity and development.

Thus there is a strong difference between interventions that help a dialogue to flourish and those that will destroy it. The fear of being affected by the latter can be strongly felt. Many teachers and students are alert to potential abuse of traces left by their "digital footprint" (Osborne and Connelly 2015). When I was a new online student, I became very conscious that some technologically-expert colleagues would never allow their images to appear online. Yet even such reluctant web participants cannot control what others say about their "uncontainable self" (Barbour and Marshall 2012), when friends tag them in photos or students comment on their courses.

Many of today's face-to-face teachers may in fact have little option but to submit themselves to potentially public gaze online. While ten years ago, some university teachers could tell me that they did not want to engage with digital teaching because they disliked the way people's (especially women's) images were treated online, they perhaps have less choice now. For example, in many cases, classes must be recorded, for ostensibly excellent egalitarian reasons - to allow students to review the lecture later. This has become a mainstream practice for some classes, along with preloading of slides, equations and definitions to a learning management system. It can be difficult to refuse, as the requirements have legal and moral implications that supersede any personal misgivings or teaching preferences. 
The need for compliance is also associated with a well-documented fear of new managerialism in Higher Education, and the relationship of technology to this (Clegg 2003). As well as ensuring that academic teachers comply with equalities policy, the resulting videos could possibly be used for monitoring and surveillance of teaching practices that have hitherto been unscrutinised. These are very real fears expressed by academics; at the time of writing it is unclear how realistic they are. But the performativity inevitably associated with video is likely to feed into already pervasive fears affecting teachers' identity (Ball 2003).

Performance is perhaps more of a feature of my second video clip than my first. We made two Google hangouts in the first run of our MOOC, and their strong endorsement by students suggested that we should do more for the next run, and further explore the impact of the visual teacher presence. We also decided to create video introductions to each week, in relevant locations in and near the University of Edinburgh, in order to locate ourselves.

Additional file 1: Video S1: Appearance 2: On location

\section{Performance, presence and intimacy}

When videos were recorded specifically for the MOOC, the University of Edinburgh did adopt the high production values expected by Coursera. The professional recording does not disguise that I am not a natural television presenter, but the ums and ahs could at least be cut out, unlike in our recorded Google hangout. An empathetic producer helped me over presentation fears both in the studio and on location.

These weekly introductions seemed to get rid of the, "Where are the professors?" question. Participants could see us whenever they wanted: arguably, we had a presence. Borup et al. (2012) associate video-based teaching with a stronger sense of teacher social presence, in terms of the influential community of inquiry framework established by Garrison and his colleagues (Garrison and Anderson 2003). The expressions used by the students in the study by Borup et al. resonate with those made by my own students when I experimented further with video - the teacher seems more "real" and "human" because video is closer to face-to-face encounters. The community of inquiry framework highlights the intersection of social presence, cognitive presence and teaching presence. Teachers' presence ideally invokes all three: having social presence means that the teachers seem "real"; the cognitive presence arises from the teachers' provision of "triggering events" that stimulate exploration; and the teaching presence from the teachers' facilitation of these events and the overall discourse and management of the situation. The community of inquiry framework also applies to students' presence, for example in a sense of group cohesion, and collaborative activity.

Further light is thrown these ideas, with specific reference to MOOCs, in a paper that has particularly influenced my own decision to take my video-based presence further (Adams et al. 2014). Adams and her colleagues made a phenomenological analysis of the lived experiences of successful MOOC completers and concluded "...videos may open an unexpectedly intimate tutorial sphere with the instructor" (p. 208). Participants used expressions about their teachers such as "speaking directly to me". An interesting example was of an addition to a previously recorded lecture where the professor had later recorded an audio addendum for the MOOC saying "I made a mistake there." 
One participant felt that this had been addressed not only to all the participants but also specifically to him/herself.

The notion of how an utterance relates to an addressee is fundamental to Bakhtin's thinking, though it is a complex concept. On the surface, as each utterance is made in a particular dialogical context, it may be surprising that a recording speaks so strongly to a student. However, taking into account the "boundless past and boundless" future of a dialogue, the chains of human interactions and meanings are still present in the video form, perhaps because of its lack of attempt to be authoritative, monologic and complete.

At any moment in the development of the dialogue there are immense, boundless masses of forgotten contextual meanings, but at certain moments of the dialogue's subsequent development along the way they are recalled and invigorated in renewed form (in a new context) (Bakhtin 1986, p. 170).

I have noticed myself that even my own video can provide a useful stimulus to future thinking, rather like a reflection in a journal. A tug - between concern about permanence and the pleasure in having a reminder - settles down as the medium becomes more familiar. My fear of the monologue proved to be ill-founded. When I finally decided to face the camera to talk to my students, they reassured me that I didn't come across as monologic, but was "real" and "human".

Additional file 1: Video S1: Appearance 3: Facing my students

I deliberately started a forum thread to discuss the use of this video with my students. Because the course was about online course design, students would need to think about potential video presence in their own course designs. I also stressed the artifice behind the video production - that I was reading, that my usually quite hesitant speech could be overcome this way and through edits, that I had to spend extensive time on both producing it and getting it in a format that I could share.

It should be noted that the comments, generally positive, came from just a few students. One thing that was praised about the course was my willingness to "share the workings" of what I was doing, by talking about it. That has resonances with the MOOC professor identified by Adams et al. (2014) who said, "I made a mistake there." It may be necessary to investigate further, but it is possible that the video-presence sense of being "real" emerges because it can overcome the distancing and separating effects of print and writing (Ong 2012/1982). This is perhaps particularly the case when the video does not feel highly polished - in that case, the video does not represent closure and authority.

\section{After print: beyond the Gutenberg parenthesis}

In a coda to the 30th anniversary edition to Walter Ong's work on Orality and Literacy, John Hartley (2012) refers to the role of digital interactive media in drawing attention to the Gutenberg parenthesis (Pettit 2012). This is the view that the print era is a relatively short deviation from more open and synchronous forms of writing and, especially, orality. In this view, printing has had an enormous, though ultimately temporary, transformative effect on thinking: it enabled, inter alia, publishing, scholarship, individual authorship, capitalism, manageralism - indeed, our modern way of academic life, within which many powerful interests are invested. But its dominance is being challenged by newer forms, that bring back the oral tradition. 
Hartley welcomes the notion of the parenthesis in allowing us to talk about the relationships among orality, literacy and print culture and their digital successors without succumbing to a progressivist account of history and seeing printing as an "evolutionary" step. He refers to the current convergence of modes and praises Ong's contribution to identifying the cultural evolution of technologies, while resisting an interpretation of Ong that claims human consciousness has been irrevocably changed in the process (which would imply technological determinism). I find this useful on two counts:

- I am alerted by Ong's work to my former immersion in print culture and the slow release of its hold on me through the exposure to newer forms that began with my online student experience;

- Hartley's coda to the work helps me to see the possibility of using co-existing forms of media literacy in an informed way in our emergent cultural and educational environments - recognizing the varying contributions video and other forms can make.

In practical terms, this line of thinking means a recognition of the liberating effect that use of video can offer, for increase opportunities for engaging in dialogues with my students. While still relishing the acts of reading and writing, I can supplement these with alternative media which many prefer and which also remain dormant in those of us steeped in print. In moving on from more closed forms of intellectual participation, I can draw on Bakhtin's notions of the monologic and the dialogic - and especially the nuanced potential interplay between their forms, functions and opportunities for ensuring continued and boundless interaction.

The stronger understanding that Ong has given us through his distinctions between oral and literate practices can help us to see how we can think differently, but they do not ultimately change what we are. The unpleasant characteristics of those who choose to troll us or submit us to surveillance are there in humans already (Naughton 2000); we should pay attention to the cultures that give rise to them rather than reject the media through which they are expressed, especially when these media can be used for better alternative purposes. While remaining wary of attempts to confine or fossilize my interactions through monologising or managerialist practices, I am optimistic that the majority of people I work with are not going to abuse the medium of video to ridicule me, make me conform or to replace me with a closed recording.

The significance of the oral tradition and its relationship to writing was important to Bakhtin too, and is shown in his undiluted admiration of the Socratic dialogues (Bakhtin 1981). While Socrates argued against writing in the Phaedrus and other works, Plato's working of Socratic dialogues into a further dialogized framework provided a testament to the survival through novel forms of the "living word" (a construct used both by Socrates and Bakhtin). New forms of weaving text, image and movement offer exciting prospects for the living word; the appearance of the online teacher will have a small, but potentially significant, role.

\section{Conclusion}

So, as an individual teacher my challenge now is to work out how to use video to engage in dialogue as well as (or instead of) transmitting information - and to support colleagues 
and students who have genuine fears of misrepresentation or surveillance. The video will not be a proxy for for the teacher: rather it will be part of the dialogic repertoire of teachers and students. I now recognize that video can be used to create a sense of closeness and shared dialogue between people and is not necessarily inimical to a dialogic stance for teaching. Moreover, it is becoming an essential part of our research and dissemination practices. I have tried to express this in spoken language in my final clip.

Additional file 1: Video S1: Conclusion

\section{Additional file}

Additional file 1: Visual pedagogies. (MP4 438319kb)

Abbreviations

EDCMOOC: E-learning and digital cultures MOOC, University of Edinburgh; MOOC: Massive open online course

\section{Acknowledgements}

The author wishes to acknowledge the support of her colleagues from EDCMOOC who appear in the Google Hangout in the first video extract: Sian Bayne, Jeremy Knox, Hamish Macleod and Jen Ross. She is also grateful to an anonymous reviewer for constructive feedback on a draft of this paper, and to Petar Jandric for his encouragement to participate in the first conference of the Association for Visual Pedagogies in Zagreb, June 2016.

\section{Competing interests}

The author declares that she has no competing interests.

Received: 16 June 2016 Accepted: 23 September 2016

Published online: 24 October 2016

\section{References}

Adams C, Yin Y, Madriz LFV, Mullen CS (2014) A phenomenology of learning large: the tutorial sphere of xMOOC video lectures. Distance Educ 35(2):202-216

Bakhtin MM (1984) Problems of Dostoevsky's Poetics. University of Minnesota Press, Minneapolis

Bakhtin MM (1986) In: Emerson C, Holquist M, McGee V (eds) Speech genres and other late essays. University of Texas Press, Austin Bakhtin MM (1981) in Holquist M (ed) The dialogic imagination: Four essays by MM Bakhtin. University of Texas Press, Austin Ball S (2003) The Teacher's Soul and the Terrors of Performativity. J Educ Policy 18(2):215-228

Barbour K, Marshall D (2012) The academic online: Constructing persona through the World Wide Web. First Monday. doi:10.5210/fm.v0i0.3969

Borup J, West RE, Graham CR (2012) Improving online social presence through asynchronous video. Internet High Educ 15(3):195-203

Clegg S (2003) Learning and teaching policies in higher education: mediations and contradictions of practice. Brit Educ Res J 29(6):803-819

Garrison D, Anderson T (2003) E-Learning in the 21st Century. RoutledgeFalmer, London

Hartley J (2012) After Ongism. In: Ong W Orality and LIteracy: 30th Anniversary Edition Routledge, Oxon

Herring S, Job-Sluder K, Scheckler R, Barab S (2002) Searching for safety online: managing "Trolling" in a feminist forum. Inform Soc 5:371-384

Kanuka H, Anderson T (1999) Using constructivism in technology-mediated learning: constructing order out of the chaos in the literature. Int J of Radical Pedagogy 1(2). http://radicalpedagogy.icaap.org/content/issue1_2/02kanuka1_2.html. Accessed 2 Oct 2016

Knox J (2016) Posthumanism and the massive open online course. Routledge, Abingdon

Knox J, Bayne S, Macleod H, Ross J, Sinclair C (2012) MOOC pedagogy: the challenges of developing for Coursera https:/altc.alt.ac.uk/blog/2012/08/mooc-pedagogy-the-challenges-of-developing-for-coursera/. Accessed 14 June 2016

Macleod H, Sinclair C, Haywood J, Woodgate A (2016) Massive open online courses: designing for the unknown learner. Teach High Educ 21(1):13-24

MOOCs@Edinburgh (2013) MOOCs@ Edinburgh 2013: Report \#1.https://www.era.lib.ed.ac.uk/bitstream/handle/1842/ 6683/Edinburgh_MOOCs_Report2013_no1.pdf?sequence=1\&isAllowed=y.

Naughton J (2000) A brief history of the future. Phoenix, London

O'Connor C, Michaels S (2007) When is dialogue 'dialogic'? Hum Dev 50:275-285

Ong W (2012) Orality and Literacy: 30th Anniversary Edition. Routledge, Oxon

Osborne N, Connelly L (2015) Managing your digital footprint: possible implications for teaching and learning. Eur Conf on Social Media, Porto, Portugal

Pettit T (2012) Media dynamics and the lessons of history: the "Gutenberg Parenthesis" as Restoration Topos. In: Hartley J, Burgess J, Bruns A (eds) A companion to new media dynamics. Malden, Wiley-Blackwell, MA and Oxford

Ronson J (2015) So you've been publicly shamed. Picador, London 